\title{
Application of Remote Control Technology for a Homogenizing Vacuum Machine
}

\author{
Ayrat Irekovich Badriev \\ Degreeless, Assistant, Automotive Department, Higher Engineering School, Naberezhnye Chelny Institute of KFU, \\ ${ }^{1}$ Kazan Federal University, \\ Scopus ID: 57198780170, ORCID: https://orcid.org/0000-0002-6963-5149
}

\begin{abstract}
An increase in the efficiency of a technological process for the production of mayonnaise products by means of remote information access is considered. The scheme of information flows in the software and hardware complex for interaction between equipment assemblies and mechanisms and software has been developed. The dispatcher's software interface has been developed for real time monitoring the technological process of manufacturing mayonnaise products. Software modules for tracking failures and malfunctions, including user settings for an automated homogenizing vacuum machine are developed. A recipe editing module has been developed in the program for making mayonnaise products. A remote system of operator's access to work and restriction of rights to control functions, setting the modes of a homogenizing vacuum machine by means of user authorization has been developed. An automated system for alerting of emergency and warning situations by means of messages and sound signals has been developed. It is proposed to store in a relational database current and retrospective messages, and indications of process parameters for the production of mayonnaise products. A system of trends for real time monitoring and analysing the dynamics of changes in process parameters is proposed. It is proposed to record the data on the varieties produced and the number of production cycles, the reasons for downtime, equipment failures and malfunctions in the daily reporting system.
\end{abstract}

Keywords: Efficiency Improvement, Automation, Mayonnaise Production, Software, Homogenization

\section{INTRODUCTION}

Today, in the age of industry 4.0, special attention is paid to the issues of increasing the efficiency of production, since they take an increasing informational nature $[1,2]$. Of course, this is primarily due to the use of new information approaches to solving production problems, which is due to the improvement of information technology, software and hardware, etc. The use of new information and technical equipment in production automation can significantly increase the volume and quality of products, as well as increasingly reduce the participation of personnel in production [3]. However, due to the nature of production, it is not always possible to completely eliminate the human factor, which entails additional control over the operator. The paper discusses the improvement of an automated control system for a homogenizing vacuum unit during the production of food products such as mayonnaise, using remote access information tools.

\section{METHODS}

The object of the research was an automated homogenizing unit for the manufacture of mayonnaise of different varieties. The unit is a system of assemblies and mechanisms, the main component of which is a vacuum tank with a mixer. The tank is equipped with actuators that serve to supply water and vegetable oil, create a vacuum, homogenize and unload the finished product. Additional reservoirs are funnels for feeding vinegar solution and egg yolks. The principle of making mayonnaise in such a unit is as follows: components (water, oil, egg yolks, and vinegar solution) are loaded into the tank according to a strict sequence and under a certain pressure, and re-mixed with a mixer for a specified time. At the end of the time cycle for making the first portion of mayonnaise, the operator checks the product for quality and decides to unload the finished product into storage tanks.

Despite the fact that the automated homogenizing plant prepares the product in an automatic mode, some of the work remains with the operator, for example, emergency stop actions or product quality control. Since mayonnaise is a product that has a shelf life, the task arose of organizing reporting for each shift of both quantitative and qualitative parameters of different varieties of manufactured product.

The solution to these problems was the development of a program for remote monitoring and control of an automated homogenizing vacuum unit. The software was implemented using the SCADA system "WinCC" developed by Siemens Company. For clarity, Figure 1 shows a diagram of information flows of the technological process automation for manufacturing a product using remote access technology. 
International Journal of Engineering Research and Technology. ISSN 0974-3154, Volume 13, Number 11 (2020), pp. 3464-3468

(C) International Research Publication House. https://dx.doi.org/10.37624/IJERT/13.11.2020.3464-3468

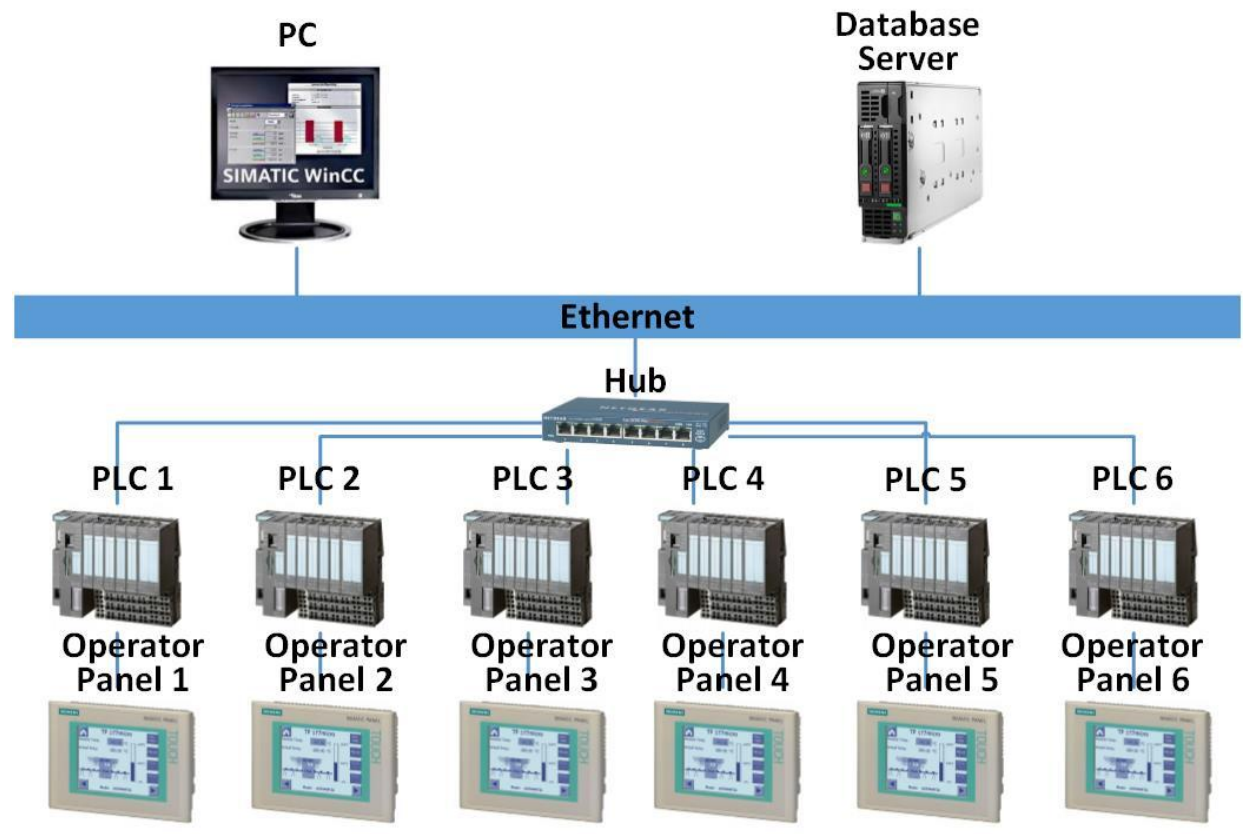

Fig 1. Diagram of information flows

The information flow diagram shows an operator panel and an industrial controller for controlling the homogenizing vacuum unit, which are interconnected by a network hub using Ethernet technology. The data is transmitted to the dispatcher's workstation and is displayed in real time. A database server is used for retrospective access and storage of information

The state of the technological process is displayed on a personal computer monitor in three different forms: in the workspace diagram, in trends (time graphs) and in an emergency message log. The main window of the workspace is shown in Figure 2.

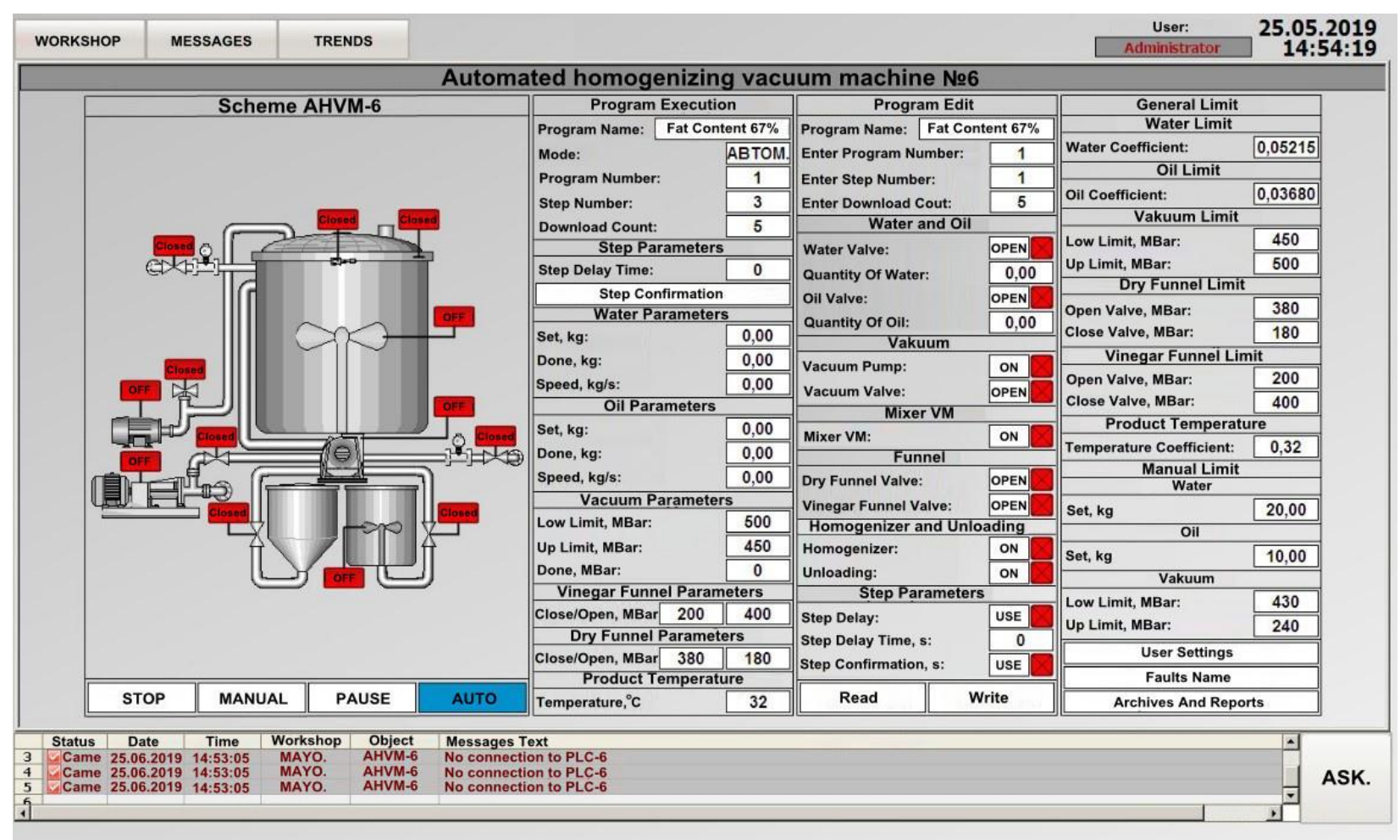

Fig 2. Main window of the monitoring and control program 
The developed application allows a remote access manager to monitor the process of making mayonnaise in real time. The program provides for authorization, which gives the right to fully control the homogenizing vacuum unit. That is why the dispatcher is the main link for setting the operator's action mode during the working shift. Thus, the dispatcher includes operators in the list of workers allowed to work and assigns them the necessary production volume at a certain period of time. At the same time, the application provides for the access isolation of operators with regard to the control and adjustment functions of the vacuum machine. Each group of operators is given the opportunity to perform only those actions to which they are accessed. If the operator needs to gain access to the control and configuration functions of the machine, he/she must obtain permission to work, namely, login and password from the dispatcher.

We can see four areas on the main screen: the diagram of the homogenizing vacuum machine, the program execution area, the program editing area, and the general setting area. The unit diagram area reflects a graphic image of the machine, as well as the state of components and mechanisms. At the same time, an authorized dispatcher uses buttons to control the modes: "Stop", "Automatic", "Manual" and "Pause". The dispatcher can display in the program execution area the parameters of the program that is currently executing. This allows us to monitor the process of making mayonnaise and equipment downtime. Here we can see the online parameters for the cycle time of the product manufacturing, the loading of water and oil, the vacuum parameters in the machine and in the funnels for dry additives and vinegar.

In the program editing area, the dispatcher sets the parameters according to which the recipes for different varieties of mayonnaise are executed. It includes step settings for the product cycles, water and oil supply, vacuum settings, and for dry addition funnels and vinegar funnel. The product manufacturing process requires a certain temperature regime, which is monitored by a temperature sensor and displays its value in the current area. Each program is individual; up to 20 product recipe programs can be recorded.

Water and oil counters are adjusted in the area of general settings using a coefficient; the upper and lower vacuum limits are set both for the tank and for dry additive and vinegar funnels. Changing the settings is only available to the operator with access rights.

In the lower part of the display space there is a window with alarm and warning messages. When the messages appear, the parameters that caused the alarm and the indicator to the right of the call button of the mnemonic diagram, on which those parameters are displayed change colour and start blinking simultaneously with their appearance. The indicator flashes until the corresponding message is acknowledged. If the signal does not return to normal by the time of acknowledgment, the indicator will remain on until the signal condition returns to normal. The appearance of the message is also accompanied by the sound signalling.

Sound alarm allows the operators to respond quickly to a defect or malfunction of equipment, to possible machine accidents, etc. The dispatcher independently determines the degree of threat, on the basis of which he/she can stop the manufacturing process. Alarms and fault messages are classified as alarm messages. Therefore, the system issues an alarm sound signal to notify the operator, when the messages occur. It should be noted that the general list of messages is available in a separate window, which can be accessed by clicking the "Messages" button. Its screen form is shown in Figure 3 .

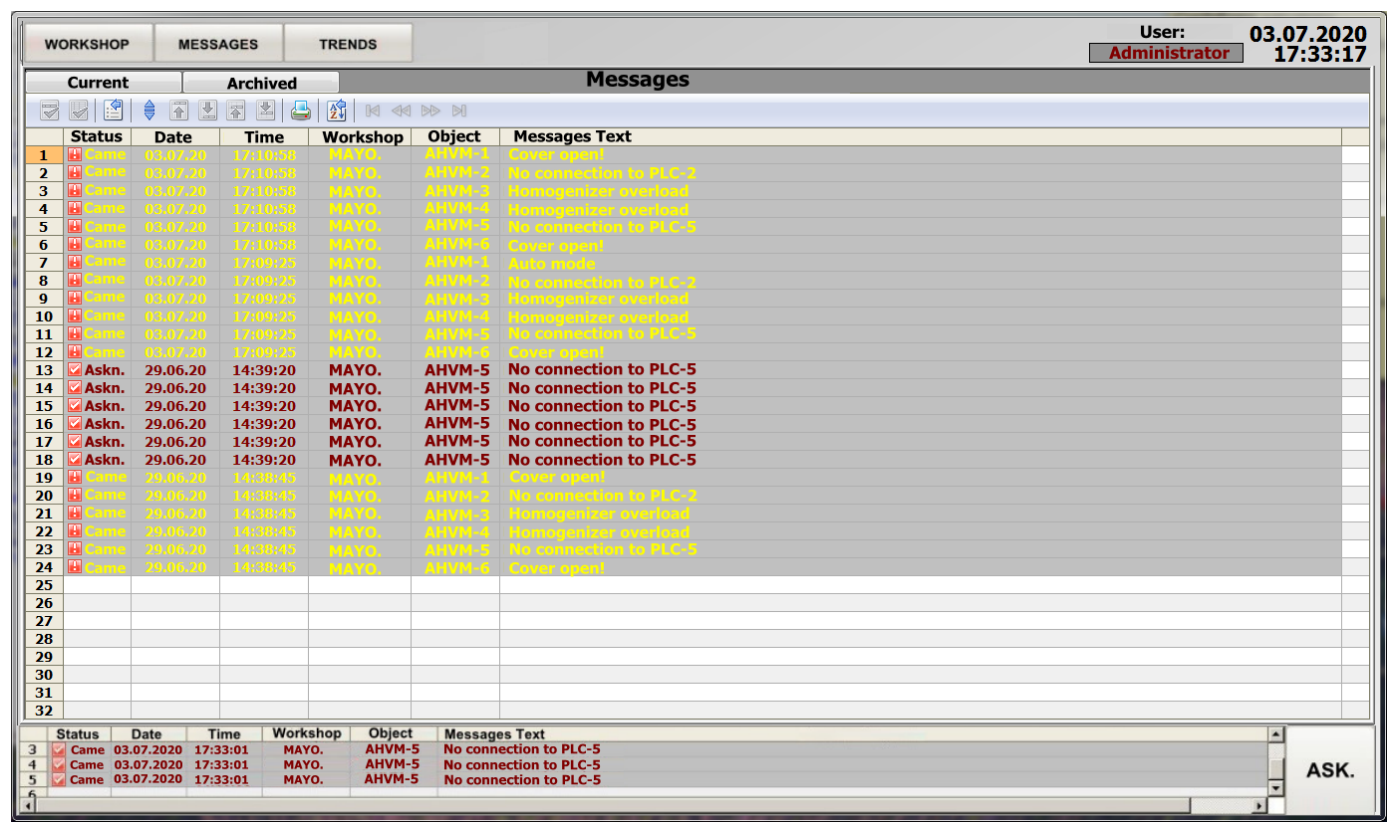

Fig 3. Message system window 
The message system maintains an archive with a time depth of 1 year. It is possible to view current (short archive) messages and retrospective (long archive) messages of various types and reasons for equipment downtime: "Replacement of the mechanical seal of the homogenizer"; "The machine does not hold well or gains vacuum"; "Breakdown of the vacuum pump"; "Replacement of the sealed contact of the oil or water meter", etc.

A trend system is provided for individual monitoring of each from the set of mayonnaise production parameters. It allows monitoring dynamic changes, for example, opening and closing of the sunflower oil supply valve (Figure 4).

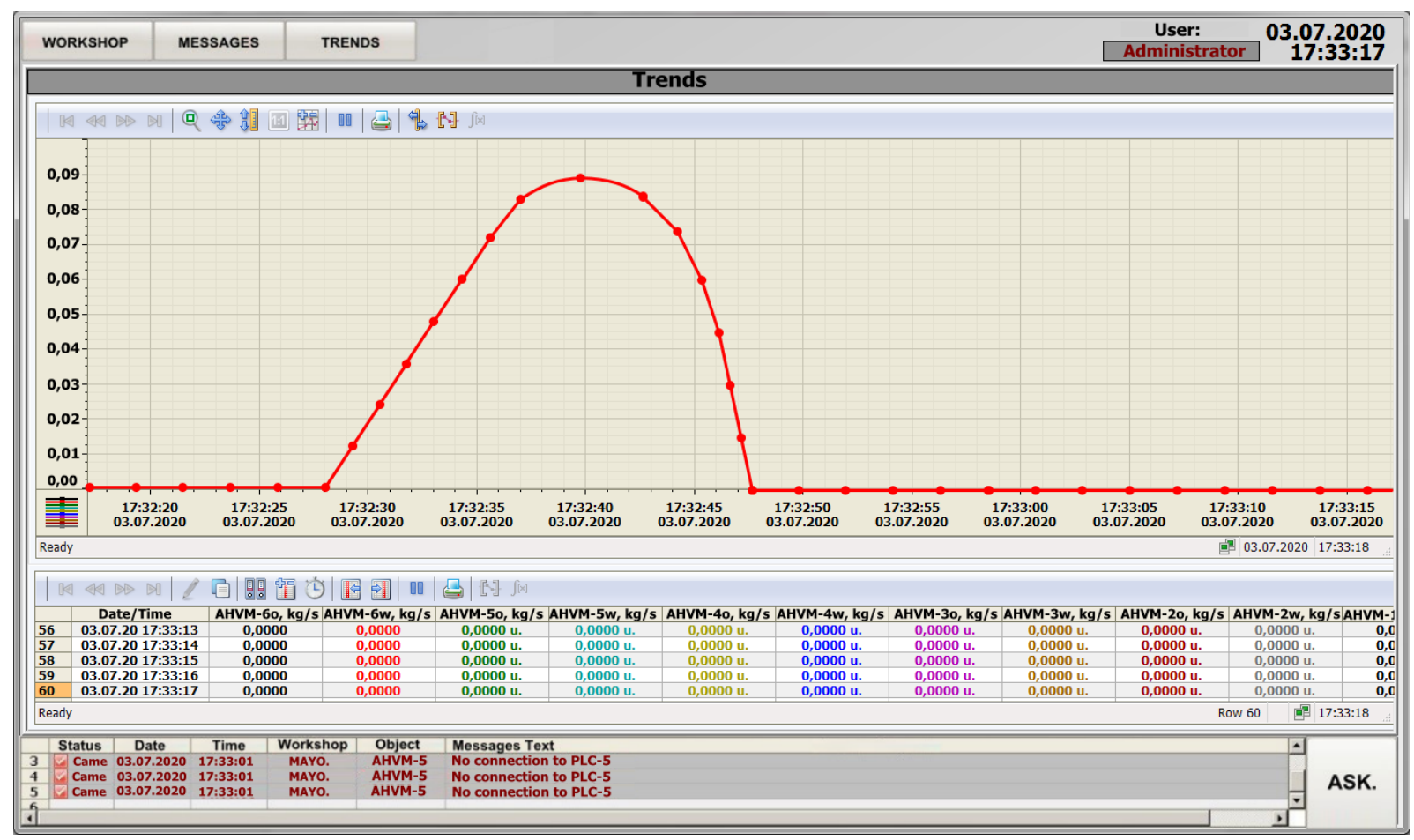

Fig 4. Trend window

The accumulated data is ultimately summarized in a reporting system, which is generated when pressing the "End work shift" button. Reports are necessary for operators to report on the work done for a certain time, usually for a shift. The report includes information on the varieties produced and the quantity of the mayonnaise preparation cycle, process errors that occurred and the reasons for the downtime of the homogenizing vacuum machine, as well as the consumption of sunflower oil. Each parameter is recorded with the date, operator name, recipe name and number of cooking cycles. For each type of report, there is the possibility of data export and printing.

\section{RESULTS AND DISCUSSION}

As a result, a remote access program has been developed with a wide range of monitoring and control capabilities for the manufacture of mayonnaise products. This will allow keeping an archive of the production data on different varieties of mayonnaise with a time depth of 1 year, monitoring the dynamics of the operation of individual equipment units and keeping a record of the work of each operator. At the same time, it is possible to monitor the manufacturing process in real time from any computer, phone or tablet.

\section{SUMMARY}

The remote monitoring and control program has improved production efficiency through timely response to process failures and downtime of the homogenizing vacuum machine.

\section{CONCLUSIONS}

Remote control and the monitoring of the manufacturing process has become an integral part of various industries, which makes it possible to improve both quantitative and qualitative characteristics of the production process for manufacturing mayonnaise.

\section{ACKNOWLEDGEMENTS}

The work is performed according to the Russian Government Program of Competitive Growth of Kazan Federal University.

\section{REFERENCES}

[1] Blagoveshchenskaya MM, Zlobin LA. Information technologies of industrial process control systems. M.: Higher school, 2005:768 p. 
[2] Berrie PG. Sensors for automated food process control: an introduction. InRobotics and Automation in the Food Industry 2013 Jan 1 (pp. 36-74). Woodhead Publishing.

[3] Caldwell DG, editor. Robotics and automation in the food industry: Current and future technologies. Elsevier; 2012 Dec 3.

[4] Ashmarova OV, Fedulova EA. Possibilities of using automated information management systems for food industry enterprises. Technique and technology of food production, 20162; (41):170 - 176.

[5] Bai C, Dallasega P, Orzes G, Sarkis J. Industry 4.0 technologies assessment: A sustainability perspective. International Journal of Production Economics, 2020; 229.

[6] Baklanov KV, Baklanov VA, Tyrsin YuA. Comparison of homogenizing devices for the production of mayonnaise . Oil and fat industry, 2008;3: 30-32.

[7] Kazemi Z, Safavi AA, Pouresmaeeli S, Naseri F. A practical framework for implementing multivariate monitoring techniques into distributed control system. Control Engineering Practice, 2019;82: 118-129.

[8] Rakhimova EI, Sirotkin AS, Valiullova AA. Methodological approaches to assessing the resistance of mayonnaise to oxidative damage based on the results of its physicochemical indicators. Technology and commodity science of innovative food products, 2019;2(55): 98-103.

[9] Bronnikova VV. The use of functional additives in the formulation of low-calorie mayonnaise. Fundamental and applied research of the cooperative sector of the economy, 2015; 2: 123-126.

[10] Selman JD. Process monitoring and control on-line in the food industry. Food Control, 1990; 1(1):36-39.
Ayrat Irekovich Badriev works as a teacher, conducts lectures and workshops in the field of information systems and technologies. At the same time, the author has a certain practical experience. He has been working for a long time as a leading software engineer in the field of automation of technological processes and information technology. The developed software products have been introduced and operated in more than 10 production facilities in various industries. 